\title{
Absolute sucrose incentive reduction: Frustration or demotivation?
}

\author{
ROBERT E. PRYTULA and WILLLAM G. \\ BRAUD, University of Houston, Houston, \\ Tex. 77004
}

A group of eight male albino rats was given 20 double runway trials in which the first goal box contained $0.50 \mathrm{cc}$ of a $16 \%$ sucrose solution; these Ss were then given 10 postshift trials in which GBI reinforcement was reduced to zero. Two eight-S nonshifted control groups received $0.50 \mathrm{cc}$ of sucrose or no reinforcement, respectively, throughout the two phases. Preshift second runway speeds varied inversely with amount of $G B 1$ reinforcement. Upon reinforcement termination, the shifted group's RW2 speeds increased, but did not exceed the performance of the always-nonreinforced control group. The results suggested a demotivation rather than a frustration interpretation.

Clifford \& Schindelheim (1968) recently reported an apparent "frustration effect" in a double runway in which a sucrose solution served as the positive reinforcer. Their female hooded rats ran significantly faster in the second runway (RW2) following nonreinforcement in the first goal box (GB1) than following reinforcement in GB1. This increased response vigor following nonreinforcement may be attributed to the motivational properties of a frustration reaction (Amsel, 1967). Alternatively, according to an interpretation originally suggested by I. E. Farber (see Amsel \& Roussel, 1952, Footnote 3) and elaborated by Seward, Pereboom, Butler, \& Jones (1957), the difference in RW2 running speed following reinforcement and nonreinforcement may be due, not to a motivational increment on nonreinforced trials, but rather to a motivational decrement ("demotivation") on reinforced trials.

Since the Clifford-Schindelheim (1968) study lacked the controls necessary to assess the contribution of a possible demotivation factor, and since Ison (1968) has provided convincing evidence that sucrose reductions, in contrast to solid food reductions, may not produce frustration, the present study was conducted. Here, an appropriate demotivation control group was included in the design.

\section{SUBJECTS}

The Ss were 24 male albino rats of the Cheek-Houston strain which were 80-90 days old at the beginning of training. The Ss were caged individually and were main- tained at approximately $80 \%$ of their initial ad lib body weight throughout the experiment. Water was available continuously in the home cage.

\section{APPARATUS}

The experimental space was a wooden straight double runway, 4 in. wide and $61 / 4$ in. high. The lengths of its components were as follows: start segment( 1$), 9$ in.; run segment(1), 23.5 in.; goal segment(1), 12.5 in.; start segment(2), 10.5 in.; run segment(2), 36 in.; goal segment(2), 12 in. The walls of the first runway were painted grey, the second runway black. The entire apparatus was floored with $1 / 4$-in. hardware cloth, and was covered with hinged, clear Plexiglas lids. Aluminum spoon goal cups were attached to the left walls of the goal areas. Guillotine doors prevented egress from all start and goal boxes. Locomotion times were recorded by a system of photocells, relays, and electric timers.

\section{FAMILIARIZATION TRAINING}

During an initial 10-day weightadjustment period, the $S$ s were handled for 5 min each day. On Days 11,12 , and 13, the Ss were allowed to explore the entire apparatus individually for $5 \mathrm{~min}$. During this exploration period, sucrose was present as indicated below.

\section{PRESHIFT TRAINING}

On Days 14, 15, 16, and 17, all Ss were given five daily double-runway trials. The eight Ss of nonshifted control Group 1 always received $0.50 \mathrm{cc}$ of sucrose solution in GB1; the eight Ss of nonshifted control Group 2 (demotivation control) were never

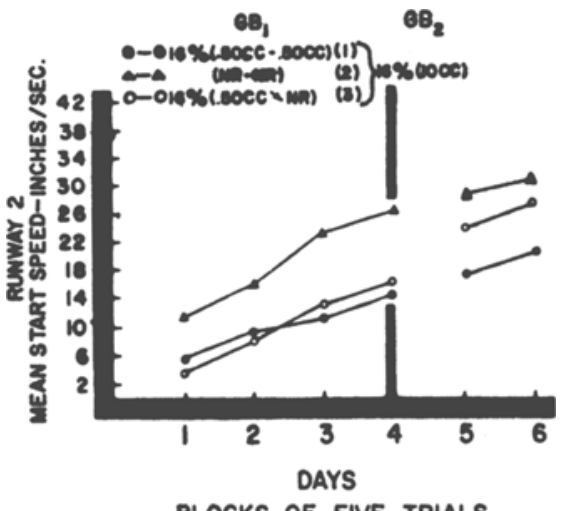

Fig. 1. Mean start speed in the second runway for both pre- and postshift trials. The symbol NR indicates nonreinforcement in the first goal box. reinforced in GB1; the eight Ss of experimental Group 3 (the to-be-shifted group) always received $0.50 \mathrm{cc}$ of sucrose solution in GB1. All 24 Ss received $0.10 \mathrm{cc}$ of sucrose solution in GB2 on all trials. In all cases, the positive reinforcer consisted of a $16 \%$ by weight sucrose-distilled water solution maintained at room temperature. POSTSHIFT TRAINING

On Days 18 and 19, all Ss were given five additional daily trials. Groups 1 and 2 continued as in the preshift phase. The Ss of Group 3 now experienced an absolute sucrose incentive reduction in GB1: an empty goal cup, rather than $0.50 \mathrm{cc}$ of sucrose, was now present in GB 1. For all Ss, GB2 reinforcement continued as in the preshift phase.

In both pre- and postshift phases, all Ss were run in squads of six animals, with an intertrial interval of $5 \mathrm{~min}$. For all Ss, GB1 confinement duration was $8 \mathrm{sec}$.

\section{RESULTS}

Start-, run-, and goal-times for the two runways were transformed into speed scores (in/sec) prior to analysis. Of particular interest are the RW2 measures, the mean start segment component of which is presented in Fig. 1. Analysis of variance of the group data indicated significant preshift differences among the groups $(F=5.51$, $\mathrm{df}=2 / 21, \quad \mathrm{p}<.05$ ). Subsequent mean comparisons (Tukey, 1953) indicated that Group 2 (which was never reinforced in GB1) differed reliably from both Group 1 $(\mathrm{q}=4.39, \mathrm{df}=3 / 21, \mathrm{p}<.05)$ and Group 3 $(q=3.64, d f=3 / 21, p<.05) ;$ Groups 1 and 3 did not differ reliably. The postshift groups effect was also significant $(F=4.97$, df $=2 / 21, p<.05$ ), with Group 1 differing from Group $2 \quad(q=-4.12, \quad d f=3 / 21$, $p<.05)$. The pre- and postshift group effects for RW2 run speeds exactly paralleled the start speed data. There were no group differences for the RW2 goal speed measures, during either pre- or postshift phases.

A trial-by-trial inspection of the performance of the downshifted group (Group 3) indicated that the speed increment in this group was gradual and ever-increasing; the increment did not begin until the fourth postshift trial, and performance gradually increased over Postshift Trials 5 through 10.

\section{DISCUSSION}

Preshift performance in RW2 varied inversely with amount of reinforcement received in GB 1. This finding, which has also been reported by other investigators in the case of food-pellet reinforcers (Barrett, Peyser, \& McHose, 1965; McHose \& Ludvigson, 1965), is in agreement with a demotivation hypothesis: reinforcement in GB 1 reduces subsequent performance. This phenomenon may represent an uncondjtional effect, a conditioned tendency to 
remain in a reinforced area, or a combination of these.

When GB1 reinforcement is terminated, the performance of Group 3 in the start and run segments of RW2 increases. Notice, however, that the performance of this downshifted group does not exceed (in fact, does not quite reach) that of the control group which was never reinforced in GB1. While absolute food pellet reductions in GBI produce faster second runway speeds than are found in appropriate nonshifted controls, this does not appear to be the case for relative food pellet reductions (Hamm, 1967). The present findings indicate that an absolute sucrose reduction may have the functional properties of a relative foodpellet reduction: there appears to be no RW 2 speed increment beyond that attributable to the removal of some demotivational factor. A series of studies is now in progress in the Houston laboratories which are exploring the effects of relative sucrose reductions in the double runway.

In further opposition to a frustration interpretation of an absolute sucrose reduction is the lack of an immediate increment in post-nonreinforcement behavior. The increase obtained is more suggestive of a gradual adjustment of performance to a new absolute reinforcement magnitude than of a rapid motivational energization.

\section{REFERENCES}

AMSEL, A. Partial reinforcement effects on vigor and persistence. In $K$. W. Spence and J. T. Spence (Eds.), Psycholosy of learning and motivation. New York: Academic Press, 1967.

AMSEL, A., \& ROUSSEL, J. Motivational properties of frustration: I. Effect on a running response of the addition of frustration to the motivational complex. Joumal of Experimental Psychology, 1952, 43, 363-368.

BARRETT, R. J., PEYSER, C. S., \& McHOSE, J. $H$. Effects of complete and incomplete reward reduction on a subsequent response. Psychonomic Science, 1965, 3, 277-278.

CLIFFORD, T., \& SCHINDELHEIM, R. H. The frustration effect as a function of runway length. Psychonomic Science, 1968, 10, 109-110.

HAMM, H. D. Perseveration and summation of the frustration effect. Journal of Experimental Psychology, 1967, 73, 196-203.

ISON, J. R. The role of reward magnitude in two process learning theory. Paper presented at the 1968 Chicago meeting of the Midwestern Psychological Association.

SEWARD, J. P., PEREBOOM, A.C., BUTLER, B., \& JONES, R. B. The role of prefeeding in an apparent frustration effect. Journal of Experimental Psy chology, 1957, 54, 445-450.

TUKEY, J. See B. J. Winer, Statistical principles in experimental design. New York: MoGraw-Hill, 1962.

\section{An enlarged study of genotype and recovery of sex drive in male mice'}

THOMAS E. McGILL, Williams College, Williamstown, Mass. 01267

This experiment replicated a previous study which showed that genotype affects the time required to recover sex drive in the male mouse. The present study involved larger samples and more genotypes than were used in the previous study. An orderly pattern of inheritance for recovery of sex drive was found.

In a previous study (McGill \& Blight, some evidence for genetic segregation of the trait. The purpose of the present study was to replicate that experiment and to extend it by enlarging the size of the samples and the number of genotypes tested.

\section{SUBJECTS}

The first two columns of Table 1 show the strains studied and the size of the samples. With the obvious exception of the inbred parent strains, reciprocal crosses were tested in all cases. Since there were no statistically significant differences between any pair of reciprocal crosses, the results are combined for those genotypes.

APPARATUS AND PROCEDURE

The apparatus and procedure were identical to those used in the previous experiment. In brief, sexually experienced males were tested after 14 days of sexual inactivity. The tests occurred during the dark phase of a reversed light-dark cycle. The animals were observed under normal room illumination, while they were enclosed in plastic cylinders $10 \mathrm{in}$. in diam and $20 \mathrm{in}$. in height. Females in hormone-induced estrus $^{2}$ were presented to the males and the time of ejaculation was noted. Then, using fresh, unmated females, periodic tests for recovery of sex drive were conducted until the male achieved a second ejaculation. The testing schedule is shown across the top of Table 1. Males remained caged in the plastic cylinders until the occurrence of the second ejaculation. Food and water were present within the cylinders between all tests following the third hour.

\section{RESULTS AND DISCUSSION}

Table 1 presents the results of this experiment. The last column indicates the median time of recovery of sex drive for the various genotypes. As in the previous experiment, the $\mathrm{C} 57 \mathrm{BL} / 6 \mathrm{~J}$ inbred strain required significantly longer ( $t$ test and $U$ test) to recover sex drive than did the DBA/ $2 J$ males or the F 1 males. The $F 1$ again did not differ significantly from the $\mathrm{DBA} / 2 \mathrm{~J}$.

In the previous experiment, C57BL $/ 6 \mathrm{~J}$ males and Backcross males (B6D2F 1 i $\mathrm{x}$ $\mathrm{C} 57 \mathrm{BL} / 6 \mathrm{~J}$ o) were rested and retested. The resulting distributions were quite similar to those found in the first test. The Spearman rank-difference test revealed no significant correlation between the results of Test 1 and Test 2 for the C57BL/6J group. However,

Table 1

Number of Male Mice of Different Genotypes Recovering Sex Drive at Different Intervals Following the Initial Ejaculation

\begin{tabular}{|c|c|c|c|c|c|c|c|c|c|c|c|c|c|c|c|c|c|}
\hline \multirow[b]{2}{*}{ Strains } & \multirow[b]{2}{*}{$\mathbf{N}$} & \multicolumn{15}{|c|}{ Hours to Recovery } & \multirow[b]{2}{*}{ Median } \\
\hline & & 1 & 2 & 3 & 6 & 12 & 24 & 36 & 48 & 72 & 96 & 120 & 144 & 168 & 192 & 216 & \\
\hline $\mathrm{DBA} / 2 \mathrm{~J}$ & 46 & 37 & 5 & 1 & 3 & & & & & & & & & & & & 1 \\
\hline $\mathrm{C} 57 \mathrm{BL} / 6 \mathrm{~J}$ & 56 & 1 & 0 & 1 & 3 & 4 & 3 & 3 & 5 & 12 & 10 & 3 & 5 & 3 & 1 & 2 & 72 \\
\hline F1 & 116 & 74 & 15 & 16 & 8 & 1 & 2 & & & & & & & & & & 1 \\
\hline $\mathrm{F} 2$ & 195 & 76 & 10 & 9 & 16 & 13 & 14 & 4 & 8 & 12 & 11 & 5 & 2 & 6 & 6 & 3 & 6 \\
\hline F $1 \times$ DBA & 130 & 77 & 9 & 6 & 3 & 5 & 8 & 1 & 4 & 3 & 5 & 4 & 4 & & & 1 & 1 \\
\hline$F 1 \times C 57$ & 130 & 28 & 7 & 6 & 7 & 14 & 14 & 7 & 10 & 8 & 5 & 11 & 5 & 4 & 2 & 2 & 24 \\
\hline
\end{tabular}

